nephron

Experimental

Nephrology

and Genetics
Nephron 2016;133:261-269

DOI: $10.1159 / 000446879$
Received: February 18, 2016

Accepted after revision: April 24, 2016

Published online: July 30, 2016

\title{
Spleen Tyrosine Kinase: A Crucial Player and Potential Therapeutic Target in Renal Disease
}

\author{
Terry King-Wing Ma ${ }^{a}$ b Stephen P. McAdoo ${ }^{a}$ Frederick Wai-Keung Tam ${ }^{\mathrm{a}}$ \\ ${ }^{a}$ Renal and Vascular Inflammation Section, Department of Medicine, Imperial College London, Hammersmith \\ Hospital, London, UK; ${ }^{\mathrm{b}}$ Carol and Richard Yu Peritoneal Dialysis Research Centre, Department of Medicine and \\ Therapeutics, Prince of Wales Hospital, The Chinese University of Hong Kong, Shatin, Hong Kong
}

\section{Key Words}

Antibodies · Interstitial fibrosis · Glomerulonephritides .

Acute renal rejection · Immunoglobulin A nephropathy

\begin{abstract}
Spleen tyrosine kinase (Syk), a 72 kDa cytoplasmic non-receptor protein-tyrosine kinase, plays an important role in signal transduction in a variety of cell types. Ever since its discovery in the early 1990s, there has been accumulating evidence to suggest a pathogenic role of Syk in various allergic disorders, autoimmune diseases and malignancies. Additionally, there is emerging data from both pre-clinical and clinical studies that Syk is implicated in the pathogenesis of proliferative glomerulonephritis (GN), including anti-glomerular basement membrane disease, anti-neutrophil cytoplasmic antibody-associated GN, lupus nephritis and immunoglobulin A nephropathy (IgAN). Moreover, recent animal studies have shed light on the importance of Syk in mediating acute renal allograft rejection, Epstein Barr virus-associated post-transplant lymphoproliferative disease and kidney fibrosis. Fostamatinib, an oral Syk inhibitor, has undergone clinical testing in rheumatoid arthritis, refractory immune thrombocytopenic purpura, leukemia and lymphoma. The recent STOP-IgAN trial showed that the addition of non-selective immunosuppressive therapy to intensive sup-
\end{abstract}

\section{KARGER}

E-Mail karger@karger.com www.karger.com/nef

\section{(C) 2016 The Author(s) \\ Published by S. Karger AG, Basel $1660-8151 / 16 / 1334-0261 \$ 0 / 0$}

This article is licensed under the Creative Commons Attribution 4.0 International License (CC BY) (http://www.karger.com/Services/ OpenAccessLicense). Usage, derivative works and distribution are permitted provided that proper credit is given to the author and the original publisher. portive care did not improve clinical outcomes in high-risk IgAN patients. A Syk-targeted approach may be beneficial and is currently being evaluated in a phase II randomized controlled trial. In this review, we will discuss the pathogenic role of Syk and potential use of Syk inhibitor in a variety of renal diseases.

(C) 2016 The Author(s)

Published by S. Karger AG, Basel

\section{Introduction}

Protein tyrosine kinases (PTKs) play a crucial role in the regulation of cellular growth and transformation by catalyzing the transfer of $\gamma$-phosphate of ATP to the hydroxyl group of tyrosine in a protein substrate [1]. There are 2 classes of PTKs in cells, including the transmembrane receptor PTKs and non-receptor PTKs. Receptor PTKs typically have an extracellular domain responsible for binding of ligands, a transmembrane domain for anchorage and an intracellular domain for signal transduction [2]. After binding of a ligand to a receptor PTK, it triggers dimerization and autophosphorylation of the receptor, followed by activation of downstream signaling pathways [2]. Non-receptor PTKs are subdivided into 9 main families. They interact with receptor PTKs and are involved in signaling pathways which regulate 


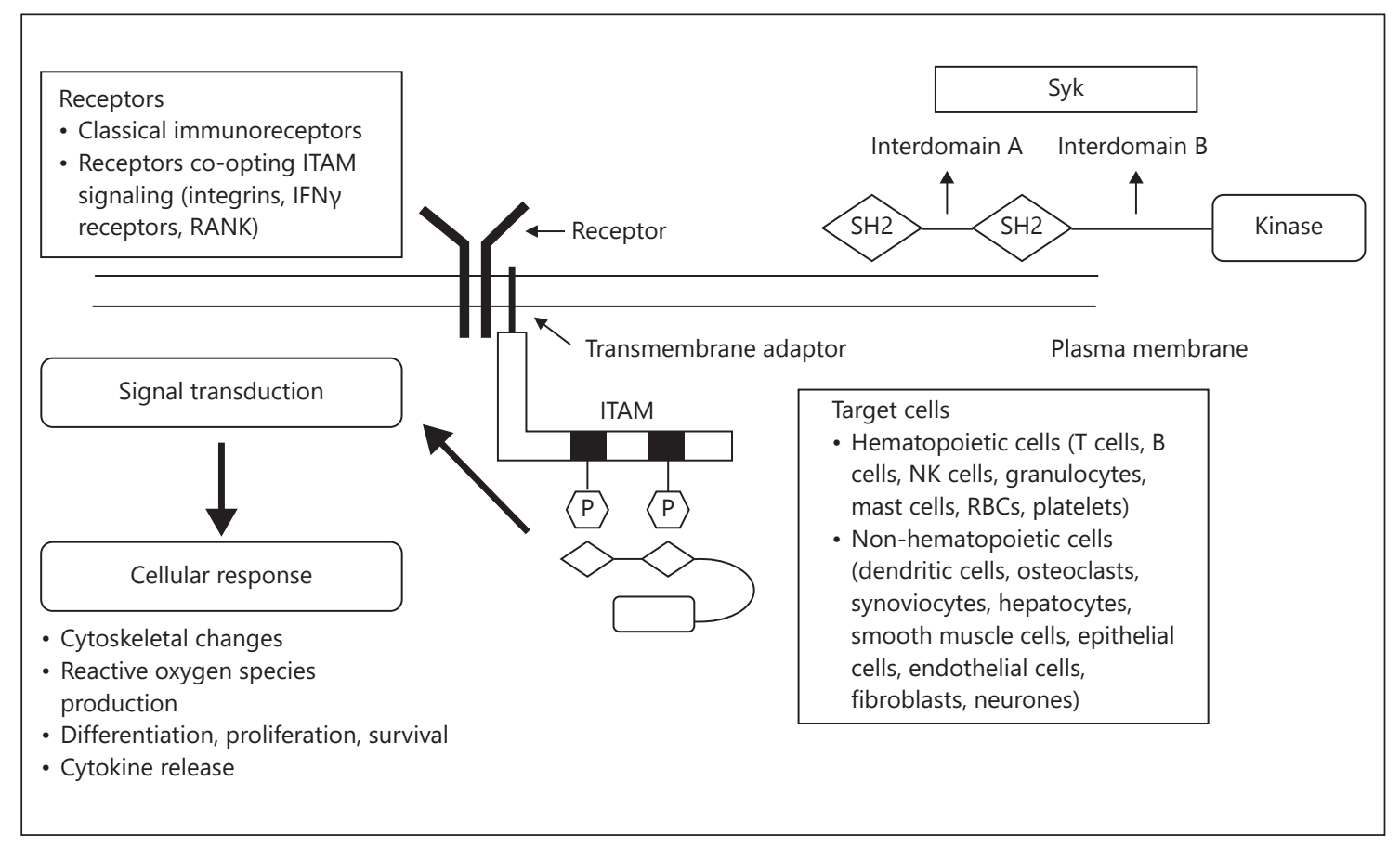

Fig. 1. Summary of the schematic structure, general mechanism of Syk activation, receptors involved and cellular responses in different cell types after activation of Syk. Recruitment of Syk to plasma membrane receptors occurs through binding of the SH2 domains of Syk to 2 phosphorylated tyrosine residues $(\mathrm{P})$ in the immunoreceptor tyrosine-based activation motif (ITAM) present in the receptor-associated transmembrane adaptor. Recruitment of Syk to dually phosphorylated ITAM triggers the activation of Syk

cellular migration, proliferative, differentiation and survival [3].

In 1990, Kobayashi et al. [4] purified a $40 \mathrm{kDa}$ cytosolic PTK which had autophosphorylation activity from porcine spleen. In 1991, Taniguchi et al. [5] showed that this $40 \mathrm{kDa}$ kinase was a proteolytic breakdown product of a $72 \mathrm{kDa}$ non-receptor PTK and cloned the spleen tyrosine kinase (Syk) gene. In 1994, the Syk gene was mapped to chromosome 9q22 in humans [6]. The Syk protein (629 amino acids) contains a pair of Src homol-

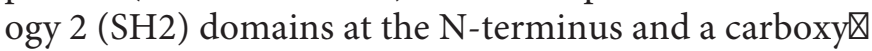
terminal tyrosine kinase domain [7]. These domains are linked by 2 linker regions: interdomain A between the 2 SH2 domains and interdomain B between the C凶terminal SH2 domain and the kinase domain. In inactive form, Syk assumes a closed, autoinhibited structure where the aromatic residues in interdomain $\mathrm{A}$, interdomain $B$ and the kinase domain interact to form a linkerkinase sandwich' [7]. Activation of Syk occurs via engagement of the $\mathrm{SH} 2$ domains or phosphorylation of ty- and activates downstream signal transduction, which eventually triggers various cellular responses. Classical immunoreceptors refer to those signaling molecules that are directly coupled to ITAM adapters FcR $\gamma$ or DAP12 through transmembrane charged residues. These immunoreceptors consist of immunoglobulin superfamily-containing proteins (such as the Fc receptors, PIR-A or the TREMs) or the C-type lectin receptors (Dectin-2, Mincle, or MDL-1). rosine residues involved in the 'linker-kinase sandwich'. Syk activation results in a conformational change that allows the exposed catalytic kinase domain to interact with downstream targets [7]. Syk is widely expressed in hematopoietic cells and involved in coupling activated immunoreceptors to downstream signaling events that mediate cellular proliferation, differentiation and phagocytosis [8]. The schematic structure, general mechanism of Syk activation, receptors involved and cellular responses in different cell types after activation of Syk is summarized in figure 1. The role of Syk in various biological functions has been comprehensively reviewed elsewhere [8].

Ever since its discovery, there has been accumulating evidence to suggest a pathogenic role of Syk in various allergic disorders, autoimmune diseases [9] and malignancies [10]. There is also emerging data from both pre-clinical and clinical studies that Syk is implicated in the pathogenesis of various renal disorders, including proliferative glomerulonephritis (GN), acute renal allograft re- 
Table 1. Summary of intervention studies of Syk inhibitor in animal models

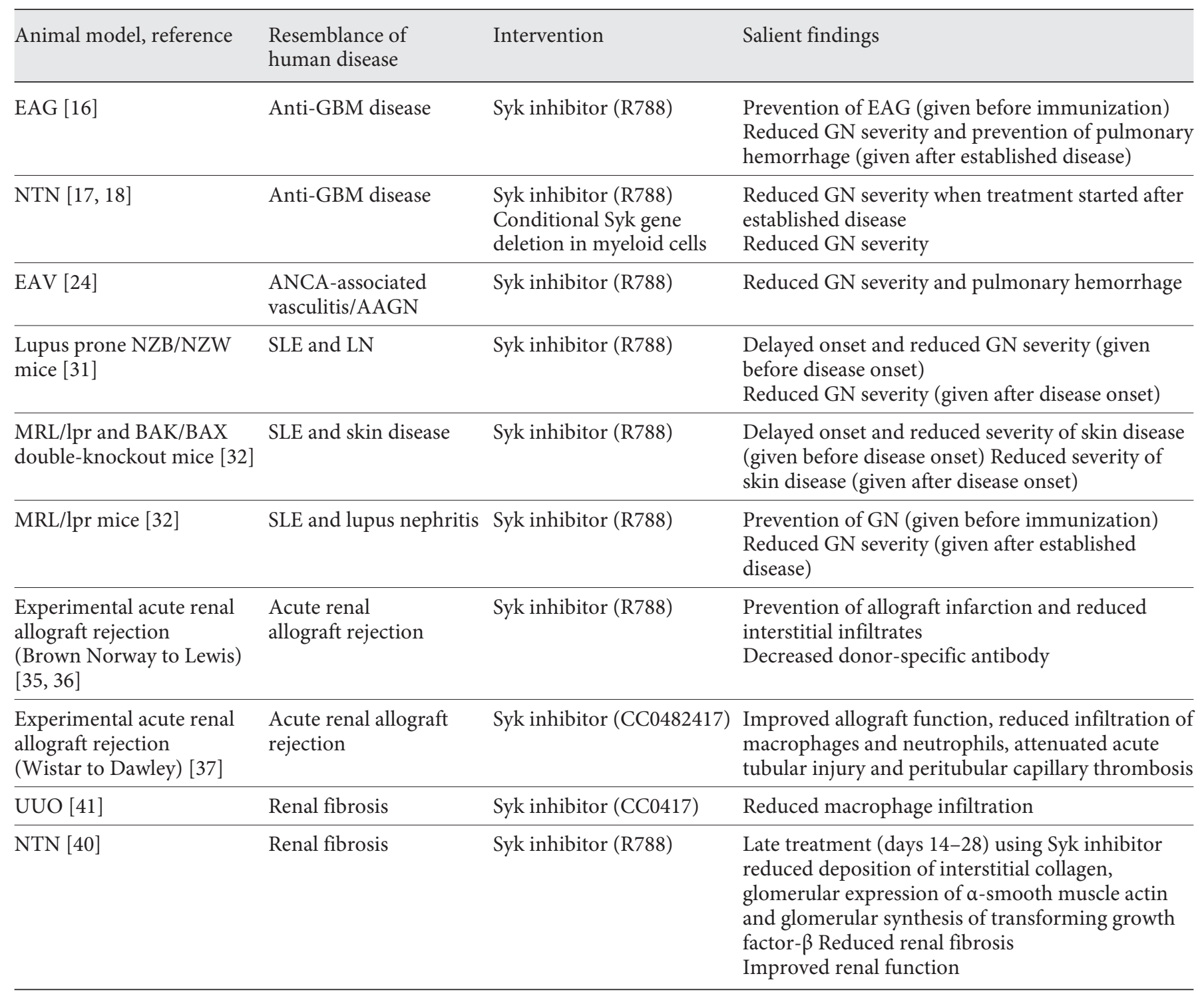

jection, Epstein Barr virus (EBV)-associated post-transplant lymphoproliferative disease (PTLD) and kidney fibrosis. Given the role of Syk in a wide range of diseases, various small molecular Syk inhibitors are being developed [11]. Fostamatinib is an oral Syk inhibitor that has been tested in clinical trials on patients with rheumatoid arthritis (RA), refractory immune thrombocytopenic purpura, leukemia and lymphoma $[12,13]$. There is an ongoing phase II randomized controlled trial to assess the safety and efficacy of fostamatinib in immunoglobulin A nephropathy $(\operatorname{Ig} A N)$. In this review, we will discuss the pathogenic role of Syk and potential use of Syk inhibitor in different renal diseases.

Syk: A Crucial Player and Potential Therapeutic Target in Renal Disease

\section{Pathogenic Role of Syk in Renal Disease (Table 1)}

\section{Glomerulonephritis}

$\mathrm{GN}$ is an important cause of acute kidney injury (AKI) and chronic kidney disease. Rapidly progressive GN (RPGN), or crescentic GN, is an aggressive disease. Antiglomerular basement membrane (anti-GBM) disease and anti-neutrophil cytoplasmic antibody (ANCA)-associated GN (AAGN) are important causes of RPGN, and Syk has been shown to play a crucial role in both conditions. Syk has also been implicated in the pathogenesis of immune complex-mediated GN, including lupus nephritis $(\mathrm{LN})$ and IgAN. 


\section{Anti-GBM Disease}

Experimental autoimmune GN (EAG) and nephrotoxic nephritis (NTN) are 2 widely used animal models that resemble human anti-GBM disease. In EAG, animals are immunized with heterologous or homologous GBM or NC1 domain of the $\alpha-3$ chain of type IV collagen. Immunized animals subsequently mount an autoimmune response and develop anti-GBM antibodies that attack their own kidneys [14]. On the contrary, there are 2 phases of injury in NTN. In the heterologous phase, animals are injected with a heterologous antiGBM antibody, which deposits in the kidney and causes transient injury. In the autologous phase, the foreign antibody acts as a planted antigen on the GBM which triggers an autoimmune response in the animal [15]. Although these models have been developed in various species, the most consistent model is that induced in Wistar-Kyoto (WKY) rats. Immunohistochemistry (IHC) study has demonstrated increased glomerular total Syk (T-Syk) and phosphorylated Syk (P-Syk) expression in EAG [16]. T-Syk includes both phosphorylated (active) and unphosphorylated (inactive) forms of Syk. Syk plays a crucial role in the activation of stress-activated protein kinases like c-Jun $\mathrm{N}$-terminal kinase and p38 mitogen-activated protein kinase, which are responsible for leukocyte-mediated renal injury [17, 18]. When NTN was induced in mice with conditional Syk gene deletion in myeloid cells, there were significantly less leukocytic infiltration, crescent formation, inflammation and fibrosis when compared with controls [19]. Administration of fostamatinib (R788), an oral prodrug of the selective Syk inhibitor tamatinib (R406), completely prevented the induction of EAG when it was given $1 \mathrm{~h}$ before immunization. When given from day 18 to 36 after induction of EAG, fostamatinib led to cessation of autoantibody production, reversal of renal injury, preservation of renal function and complete protection from pulmonary hemorrhage [16]. Additionally, fostamatinib inhibited production of proinflammatory cytokines by nephritic glomeruli ex vivo and cultured bone marrow-derived macrophages in vitro, suggesting additional therapeutic effects related to inhibited Fc receptor signaling within macrophages in diseased glomeruli which were independent of suppression of autoantibody production [16]. Similar beneficial effects of fostamatinib have also been observed in NTN models $[18,20]$. In human anti-GBM disease, previous IHC study showed increased glomerular T-Syk and P-Syk expression [21]. Syk appeared to localize to infiltrating macrophages and neutrophils. A strong correlation between glomerular T-Syk expression and serum creatinine at presentation was observed (fig. 2a). Dialysis-dependent patients had significantly higher levels of glomerular TSyk expression [21].

\section{ANCA-Associated GN}

ANCA-associated vasculitis and AAGN are characterized by the presence of antibodies directed against proteinase-3 or myeloperoxidase (MPO). In vitro study showed that ANCA-IgG induced phosphorylation of Syk in tumor necrosis factor-primed neutrophils from healthy donors [22]. Piceatannol (a Syk inhibitor) inhibited Syk phosphorylation as well as ANCA-stimulated respiratory burst [22]. Several animal models have been developed to demonstrate the pathogenicity of ANCA in vivo, as recently summarized elsewhere [23]. In experimental autoimmune vasculitis, where WKY rats are immunized with MPO, renal disease can be induced after 4 weeks [23]. Fostamatinib, given for established renal disease, significantly reduced hematuria, proteinuria, macrophage infiltration and pulmonary hemorrhage [24]. In patients with AAGN, glomerular T-Syk expression was upregulated and correlated with serum creatinine at the time of biopsy as well as the histological class of disease [21]. Four histopathological classes of lesions have been proposed for prognostication of AAGN patients, namely focal, crescentic, mixed and sclerotic [25]. T-Syk staining was highest in patients with crescentic (acute) disease but minimal in sclerotic (chronic) disease (fig. 2b) [21].

\section{Lupus Nephritis}

Systemic lupus erythematosus (SLE) is a complex, multi-system, autoimmune disease characterized by abnormalities in both $\mathrm{T}$ and $\mathrm{B}$ cells [26]. Compared with normal T cells, T cells obtained from SLE patients demonstrated substantially higher Syk expression and activity [27]. In vitro study showed that Syk was responsible for upregulation of various cytokines, receptors and enzymes involved in the immunopathogenesis of SLE, including CD44 (involved in T cell migration), interleukin (IL)-21 (involved in antibody production), OAS2 (2'-5'-oligoadenylate synthetase; involved in type I interferon response) and protein phosphatase $2 \mathrm{~A}$ (involved in regulation of IL-2 production) [28]. The cardinal abnormalities of B cells in SLE include loss of B cell tolerance resulting in autoantibody production and hyperactive $B$ cell receptor (BCR)-triggered signaling [29]. Murine models of SLE and LN are widely used and considered to be the best tool to study human SLE [30]. Fostamatinib, no matter given before or after disease onset, delayed the 


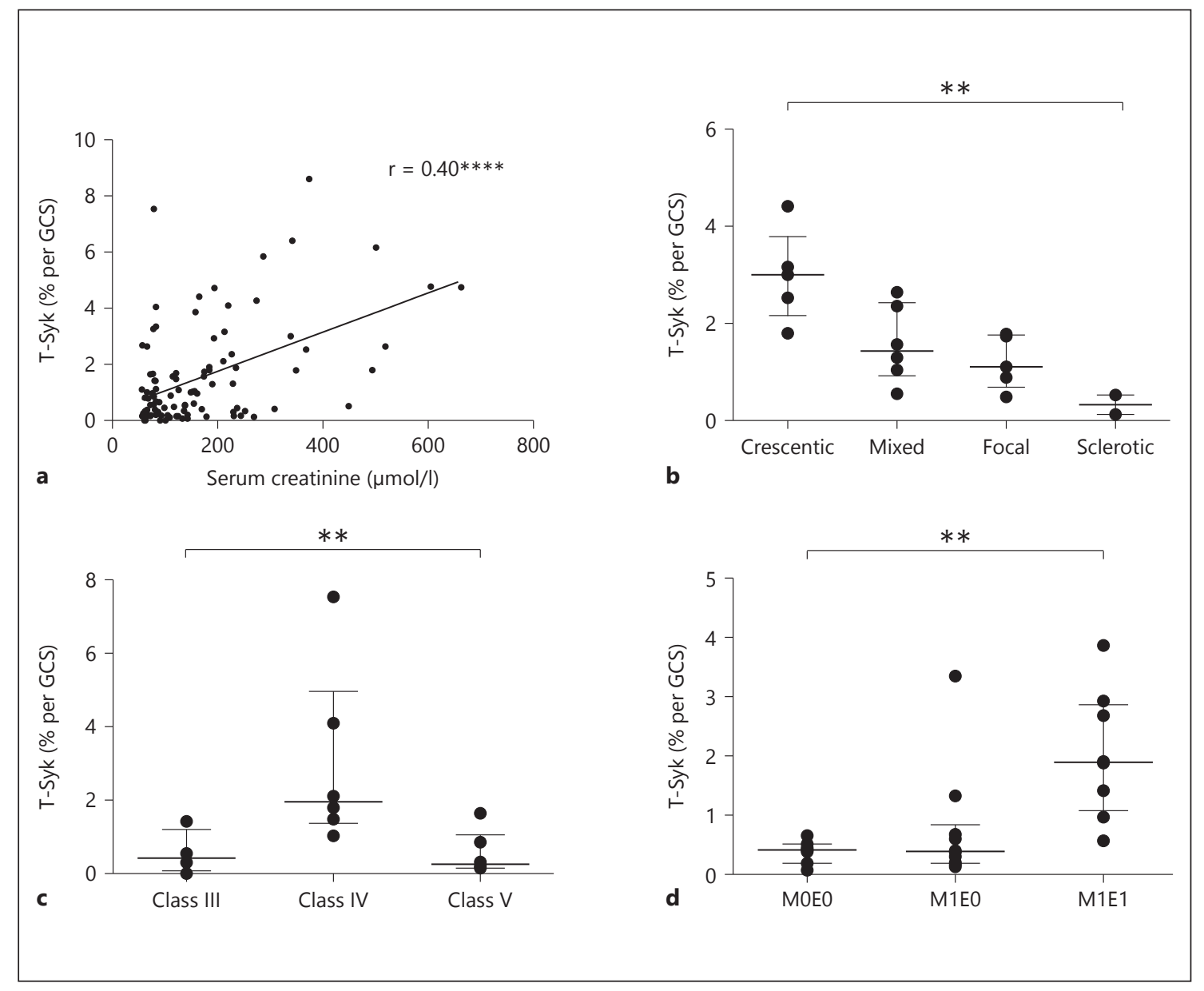

Fig. 2. Correlation between Syk expression and disease activity in proliferative GN (reproduced with permission from [21]. a Correlation between T-Syk expression and serum creatinine in human anti-GBM disease. b Correlation between T-Syk expression and histopathological classes in human AAGN. c Correlation between
T-Syk expression and histopathological classes in human LN. d Correlation between T-Syk expression and Oxford classification scores in human IgA nephropathy. ${ }^{* *} \mathrm{p}<0.01{ }^{* * * *} \mathrm{p}<0.0001 . \mathrm{E}=$ Endocapillary proliferation; GCS = glomerular cross section; $\mathrm{M}=$ mesangial hypercellularity. onset of proteinuria and azotemia, reduced renal pathology and kidney infiltrates and significantly prolonged survival in lupus prone NZB/NZW mice [31]. In MRL/ lpr and BAK/BAX double-knockout mice, fostamatinib prevented development of skin disease when given before disease onset and significantly reduced severity of skin disease when given after disease onset [32]. In MRL/ lpr mice, fostamatinib could prevent the development of renal disease and reduce proteinuria in established disease [32]. In LN patients, those with class IV (diffuse proliferative) LN had the highest T-Syk and P-Syk expressions [21]. Minimal T-Syk staining was seen in class $\mathrm{V}$ disease (fig. 2c). There was also a trend of higher T-Syk expression in patients who failed to achieve complete remission (CR) by 6 months compared with patients who achieved CR. However, there was no association between T-Syk expression and serum creatinine or proteinuria [21].

\section{IgA Nephropathy}

IgAN is the most common primary GN worldwide. A multi-hit pathogenesis model has been proposed [33]. Initially, there is increased production of galactose-deficient IgA1 (hit 1), followed by formation of autoantibodies directed against galactose-deficient IgA1 (hit 2). These autoantibodies subsequently bind with galactose-deficient IgA1 to form pathogenic immune complexes (hit 3), which deposit in the mesangium, activate mesangial cells and induce glomerular injury (hit 4). Previous in vitro study demonstrated that Syk was involved in activation of 
mesangial cell proliferation [34]. Inhibition of Syk by pharmacological antagonist (R406) and knockdown of Syk by small interfering RNA downregulated synthesis and release of a number of proinflammatory mediators and platelet-derived growth factor, and reduced cellular proliferation in mesangial cells stimulated with IgA1 isolated from IgAN patients [34]. In IgAN patients, those with endocapillary proliferation demonstrated highest levels of T-Syk staining, whereas those without proliferative features or mesangial proliferation only had negligible staining within the glomerular tuft (fig. 2d) [21]. In this study, there was no association between T-Syk expression and serum creatinine or proteinuria. However, a recent study found a significant correlation between the number of P-Syk positive glomerular cells and the degree of proteinuria and renal function in patients with IgAN, further supporting the role of Syk activation in the pathogenesis of IgAN [19].

\section{Other Renal Diseases}

In recent years, various animal studies have shed light on the pathogenic role of Syk in acute renal allograft nephropathy, EBV-associated PTLD, renal fibrosis and possibly diabetic nephropathy.

\section{Acute Renal Allograft Rejection}

In experimental model of early severe renal allograft rejection (Brown Norway to Lewis rats), IHC study showed that all rats with acute rejection had Syk-positive tubulointerstitial infiltrates [35]. Increased Syk expression was also detected in kidney transplant biopsies from patients with antibody-mediated rejection or T-cell mediated rejection [35]. Fostamatinib treatment has been shown to completely prevent allograft infarction and reduce interstitial infiltrates in experimental renal allograft rejection [36]. In another experimental model of renal allograft rejection, where Sprague-Dawley rats underwent bilateral nephrectomy and orthotopic renal transplant from Wistar rats, Ramessur Chandran et al. [37] showed dense leukocytic infiltration with strong Syk expression in the allograft. Administration of Syk inhibitor (CC0482417) significantly improved allograft function, reduced leukocytic infiltration and attenuated acute tubular injury and peritubular capillary thrombosis [37].

\section{Post-Transplant Lymphoproliferative Disease}

$\mathrm{EBV}$, a B-cell lymphotropic virus, is associated with a wide variety of B cell-derived lymphoid neoplasms, including PTLD. The EBV protein latent membrane protein $2 a$, which is expressed in the membrane of infected $B$ cells, mimics BCR and provides survival signals to EBVinfected cells through Syk [38]. In vitro study showed that Syk-activated PI3K/Akt signaling was required for the survival of EBV-positive B-cell lymphomas and R406 induced apoptosis and cell cycle arrest in EBV-positive PTLD cell lines [39].

\section{Renal Fibrosis}

Renal fibrosis is the hallmark of progressive renal disease. In WKY rats induced with NTN, fostamatinib treatment from day 14 to 28 (i.e., after established renal disease and entering into fibrotic phase) was shown to be effective in reducing glomerular expression of $\alpha$-smooth muscle actin (a profibrotic marker) and deposition of interstitial collagen, as well as improving renal function [40]. Ex vivo culture of nephritic glomeruli showed that Syk inhibition reduced glomerular synthesis of transforming growth factor (a pro-fibrotic cytokine) [40].

The unilateral ureteral obstruction (UUO) model in rodents generates progressive renal fibrosis. There is rapid and robust induction of renal fibrosis in obstructed kidney; hence the day 7 time point is the most commonly used end point for analysis of renal fibrosis in the UUO model. When UUO mice were treated with a selective Syk inhibitor (CC0417) from the time of surgery till day 7 , there was significantly reduced macrophage infiltration ( $50 \%)$ compared with vehicle and no treatment groups [41]. It will also be interesting to know if administration of Syk inhibitor at a later stage of UUO (e.g., day 14) will have the same inhibitory effect on the fibrotic process. It should be noted, however, that the effect of Syk inhibition on kidney function is difficult to assess in UUO.

\section{Diabetic Nephropathy}

Previous in vitro studies showed that Syk was involved in high-glucose-induced activation of nuclear factor (NF)- $\kappa B$ in human glomerular endothelial cells [42] and proximal tubular cells [43]. NF-B activation plays an important role in the signaling pathway of fibrosis. Preliminary animal study also showed a beneficial role of Syk inhibitor in autoimmune diabetes [44].

\section{Syk as a Therapeutic Target}

A search of the patent literature has revealed more than 70 filings describing the development of small molecular Syk inhibitors [11]. Fostamatinib is the first clinically available oral Syk inhibitor. After oral administration, it is rapidly converted to R406 by human intestinal 
microsomes, and only low levels of fostamatinib appear in the plasma [45]. Fostamatinib is metabolized primarily by cytochrome P450 3A4 [46]. On an average, fecal and urine excretions account for 80 and 19\% of drug excretion, respectively [45]. The terminal half-life was estimated to be $12-21 \mathrm{~h}$ and steady state is achieved after 3-4 days following twice daily administration. Co-administration with food results in delay in peak time and lower peak concentrations of R406, but without any change in overall exposure. Renal or hepatic impairment did not affect R406 exposure to a clinically relevant extent [47]. Fostamatinib is a P-glycoprotein inhibitor both in vitro and in vivo. Reported drug-drug interactions include ketoconazole, verapamil, rifampicin [46], oral contraceptives, simvastatin, rosuvastatin [48] and digoxin [49], but not warfarin [48]. The inhibitory effect of R406 is relatively specific for Syk. Although previous in vitro kinase assays showed that R406 did have inhibitory effects on other kinases (e.g., Flt3, Lyn, Lck), cell-based assays showed that the inhibitor effects were much less potent compared with Syk [50].

Fostamatinib has been investigated in multiple phase II and phase III clinical trials on RA patients [51-54]. Hypertension, diarrhea and headache were the most common adverse effects observed in these trials. The effect of fostamatinib on blood pressure elevation (mean increase of $\sim 3 \mathrm{~mm} \mathrm{Hg}$ in both systolic and diastolic) appeared to be dose dependent, and a concentration-dependent increase of blood pressure was observed with increasing R406 concentrations. Fostamatinib-induced hypertension may be attributed to increased vascular resistance, secondary to reduced vascular endothelial growth factorinduced nitric oxide release from endothelium [55]. Blood pressure usually returns to normal upon decrease in fostamatinib dose or its withdrawal. Alternatively, addition or modification of anti-hypertensive drugs can be considered.

The latest KDIGO guidelines suggest that IgAN patients with persistent proteinuria $\geq 1 \mathrm{~g}$ /day despite 3-6 months of optimized supportive therapy and estimated glomerular filtration rate $(\mathrm{eGFR})>50 \mathrm{ml} / \mathrm{min} / 1.73 \mathrm{~m}^{2}$ to receive a 6-month course of corticosteroid therapy [56]. However, this recommendation was recently challenged by results of the STOP-IgAN trial [57]. In this multicenter, open-label, randomized controlled trial, IgAN patients with persistent proteinuria $\geq 0.75 \mathrm{~g}$ /day after a 6 -month run-in period of supportive care were randomized to receive supportive care alone or supportive care plus immunosuppressive therapy for 3 years. In the immunosuppression group, patients with eGFR $\geq 60 \mathrm{ml} /$ $\min / 1.73 \mathrm{~m}^{2}$ received glucocorticoid monotherapy for 6 months, whereas those with eGFR $30-59 \mathrm{ml} / \mathrm{min} / 1.73 \mathrm{~m}^{2}$ received cyclophosphamide for 3 months and followed by azathioprine, plus a tapering course of steroid. A total of 80 and 82 patients were randomized to the supportive care and immunosuppression group, respectively. After 3 years, clinical remission (defined as proteinuria with a protein-to-creatinine ratio of $<0.2$ and stable renal function with a decrease in the eGFR of $<5 \mathrm{ml} / \mathrm{min} / 1.73 \mathrm{~m}^{2}$ ) was observed in $5 \%$ of the supportive care group, as compared with $17 \%$ in the immunosuppression group. However, there was no significant difference in the annual decline in eGFR between the 2 groups. More importantly, more patients in the immunosuppression group had severe infections, impaired glucose tolerance and weight gain. Recently, another double-blind, randomized controlled trial comparing mycophenolate mofetil (MMF) and placebo was prematurely terminated 6 months after it was observed that MMF did not significantly reduce proteinuria compared with supportive treatment alone [58]. Results of these recent studies challenged the efficacy and safety of non-selective immunosuppressive therapy in IgAN patients. It should be noted that renal biopsy data were not reported in these studies. Previous study showed that T-Syk expression was observed predominantly in biopsies with endocapillary proliferation, whereas biopsies with no proliferative features or mesangial proliferation only had negligible staining within the glomerular tuft [21]. The use of fostamatinib in IgAN patients demonstrating proliferative lesions on renal biopsies is currently being investigated in a phase II randomized controlled trial (NCT02112838). The recruitment phase is ongoing and the result is eagerly awaited. A previous phase II trial on treatment of SLE by Syk inhibitor (NCT00752999) was withdrawn prior to enrollment for business reasons.

\section{Conclusion}

Since its discovery in 1991, there have been more than 2,000 publications related to Syk. In particular, the last 10 years have witnessed an intense flowering of interest in this unique PTK. Based on the current evidence from both pre-clinical and clinical studies, we see a great potential in the development of Syk-targeted therapy for treatment of various renal diseases. More studies are required to delineate the role of Syk in other renal diseases, including other types of GN, diabetic nephropathy, tubulointerstitial nephritis and AKI. A clinical trial of fosta- 
matinib in IgAN is ongoing, and future clinical studies on the efficacy and safety of fostamatinib for the treatment of proliferative and immune complex GN are warranted.

\section{Acknowledgment}

T.K.W.-M. received scholarship for overseas training from the Hong Kong Kidney Foundation. S.P.M. was in receipt of Clinical Research Training Fellowship funded by the UK Medical Research Council (grant number: G0901997/1). F.W.K.-T. is supported by the Diamond Fund from Imperial College Healthcare Charity and
'Making Every Kidney Count' programme grant from Kidney Research UK. Part of this work was also supported by the National Institute for Health Research Biomedical Research Centre based at Imperial College Healthcare NHS Trust and Imperial College London.

\section{Disclosure Statement}

F.W.K.-T. is the chief investigator of the randomized controlled trial of Syk inhibitor in IgA nephropathy. He has received research project grants from AstraZeneca Limited, and has a consultancy agreement with Rigel Pharmaceuticals.

\section{References}

1 Hubbard SR, Till JH: Protein tyrosine kinase structure and function. Annu Rev Biochem 2000;69:373-398.

2 Hubbard SR, Mohammadi M, Schlessinger J: Autoregulatory mechanisms in protein-tyrosine kinases. J Biol Chem 1998;273:1198711990.

3 Gocek E, Moulas AN, Studzinski GP: Nonreceptor protein tyrosine kinases signaling pathways in normal and cancer cells. Crit Rev Clin Lab Sci 2014;51:125-137.

-4 Kobayashi T, Nakamura S, Taniguchi T, Yamamura H: Purification and characterization of a cytosolic protein-tyrosine kinase from porcine spleen. Eur J Biochem 1990;188:535540.

5 Taniguchi T, Kobayashi T, Kondo J, Takahashi K, Nakamura H, Suzuki J, Nagai K, Yamada T, Nakamura S, Yamamura H: Molecular cloning of a porcine gene Syk that encodes a $72-\mathrm{kDa}$ protein-tyrosine kinase showing high susceptibility to proteolysis. J Biol Chem 1991;266:15790-15796.

-6 Ku G, Malissen B, Mattei MG: Chromosomal location of the Syk and ZAP-70 tyrosine kinase genes in mice and humans. Immunogenetics 1994;40:300-302.

7 Geahlen RL: Getting Syk: spleen tyrosine kinase as a therapeutic target. Trends Pharmacol Sci 2014;35:414-422.

-8 Mócsai A, Ruland J, Tybulewicz VL: The SYK tyrosine kinase: a crucial player in diverse biological functions. Nat Rev Immunol 2010;10: 387-402.

-9 Pamuk ON, Tsokos GC: Spleen tyrosine kinase inhibition in the treatment of autoimmune, allergic and autoinflammatory diseases. Arthritis Res Ther 2010;12:222.

10 Krisenko MO, Geahlen RL: Calling in SYK: SYK's dual role as a tumor promoter and tumor suppressor in cancer. Biochim Biophys Acta 2015; 1853:254-263.

11 Norman P: Spleen tyrosine kinase inhibitors: a review of the patent literature 20102013. Expert Opin Ther Pat 2014;24:573595.
12 Scott IC, Scott DL: Spleen tyrosine kinase inhibitors for rheumatoid arthritis: where are we now? Drugs 2014;74:415-422.

13 Efremov DG, Laurenti L: The Syk kinase as a therapeutic target in leukemia and lymphoma. Expert Opin Investig Drugs 2011;20:623636.

14 Reynolds J, Mavromatidis K, Cashman SJ, Evans DJ, Pusey CD: Experimental autoimmune glomerulonephritis (EAG) induced by homologous and heterologous glomerular basement membrane in two substrains of WistarKyoto rat. Nephrol Dial Transplant 1998;13: 44-52.

15 Tam FW, Smith J, Morel D, Karkar AM, Thompson EM, Cook HT, Pusey CD: Development of scarring and renal failure in a rat model of crescentic glomerulonephritis. Nephrol Dial Transplant 1999;14:1658-1666.

16 McAdoo SP, Reynolds J, Bhangal G, Smith J, McDaid JP, Tanna A, Jackson WD, Masuda ES, Cook HT, Pusey CD, Tam FW: Spleen tyrosine kinase inhibition attenuates autoantibody production and reverses experimental autoimmune GN. J Am Soc Nephrol 2014;25: 2291-2302.

17 Sheryanna A, Bhangal G, McDaid J, Smith J, Manning A, Foxwell BM, Feldmann M, Cook HT, Pusey CD, Tam FW: Inhibition of p38 mitogen-activated protein kinase is effective in the treatment of experimental crescentic glomerulonephritis and suppresses monocyte chemoattractant protein-1 but not IL-1beta or IL-6. J Am Soc Nephrol 2007;18:11671179.

18 Ryan J, Ma FY, Kanellis J, Delgado M, Blease K, Nikolic-Paterson DJ: Spleen tyrosine kinase promotes acute neutrophil-mediated glomerular injury via activation of JNK and p38 MAPK in rat nephrotoxic serum nephritis. Lab Invest 2011;91:1727-1738.

19 Ryan J, Ma FY, Han Y, Ozols E, Kanellis J, Tesch GH, Nikolic-Paterson DJ: Myeloid cellmediated renal injury in rapidly progressive glomerulonephritis depends upon spleen tyrosine kinase. J Pathol 2016;238:10-20.
20 Smith J, McDaid JP, Bhangal G, Chawanasuntorapoj R, Masuda ES, Cook HT, Pusey CD, Tam FW: A spleen tyrosine kinase inhibitor reduces the severity of established glomerulonephritis. J Am Soc Nephrol 2010;21:231-236.

21 McAdoo SP, Bhangal G, Page T, Cook HT, Pusey CD, Tam FW: Correlation of disease activity in proliferative glomerulonephritis with glomerular spleen tyrosine kinase expression. Kidney Int 2015;88:52-60.

-22 Hewins P, Williams JM, Wakelam MJ, Savage CO: Activation of Syk in neutrophils by antineutrophil cytoplasm antibodies occurs via Fcgamma receptors and CD18. J Am Soc Nephrol 2004;15:796-808.

23 Coughlan AM, Freeley SJ, Robson MG: Animal models of anti-neutrophil cytoplasmic antibody-associated vasculitis. Clin Exp Immunol 2012;169:229-237.

24 McAdoo SP, Tanna A, McDaid J, Bhangal G, Masuda ES, Cook HT, Pusey CD, Tam FWK, et al: SYK inhibition in experimental autoimmune vasculitis and its glomerular expression in ANCA-associated vasculitis. Lancet 2014; 383:72.

25 Berden AE, Ferrario F, Hagen EC, Jayne DR, Jennette JC, Joh K, Neumann I, Noël LH, Pusey CD, Waldherr R, Bruijn JA, Bajema IM: Histopathologic classification of ANCA-associated glomerulonephritis. J Am Soc Nephrol 2010;21:1628-1636.

26 Nagy G, Koncz A, Perl A: T- and B-cell abnormalities in systemic lupus erythematosus. Crit Rev Immunol 2005;25:123-140.

27 Krishnan S, Juang YT, Chowdhury B, Magilavy A, Fisher CU, Nguyen H, Nambiar MP, Kyttaris V, Weinstein A, Bahjat R, Pine P, Rus V, Tsokos GC: Differential expression and molecular associations of Syk in systemic lupus erythematosus T cells. J Immunol 2008; 181:8145-8152.

28 Grammatikos AP, Ghosh D, Devlin A, Kyttaris VC, Tsokos GC: Spleen tyrosine kinase (Syk) regulates systemic lupus erythematosus (SLE) T cell signaling. PLoS One 2013; 8:e74550. 
29 Liossis SN, Melissaropoulos K: Molecular abnormalities of the B cell in systemic lupus erythematosus are candidates for functional inhibition treatments. Expert Opin Pharmacother 2014; 15:833-840.

30 Davidson A, Aranow C: Lupus nephritis: lessons from murine models. Nat Rev Rheumatol 2010;6:13-20.

- 31 Bahjat FR, Pine PR, Reitsma A, Cassafer G, Baluom M, Grillo S, Chang B, Zhao FF, Payan DG, Grossbard EB, Daikh DI: An orally bioavailable spleen tyrosine kinase inhibitor delays disease progression and prolongs survival in murine lupus. Arthritis Rheum 2008;58: 1433-1444.

-32 Deng GM, Liu L, Bahjat FR, Pine PR, Tsokos GC: Suppression of skin and kidney disease by inhibition of spleen tyrosine kinase in lupus-prone mice. Arthritis Rheum 2010;62: 2086-2092.

-33 Magistroni R, D’Agati VD, Appel GB, Kiryluk K: New developments in the genetics, pathogenesis, and therapy of IgA nephropathy. Kidney Int 2015;88:974-989.

- 34 Kim MJ, McDaid JP, McAdoo SP, Barratt J, Molyneux K, Masuda ES, Pusey CD, Tam FW: Spleen tyrosine kinase is important in the production of proinflammatory cytokines and cell proliferation in human mesangial cells following stimulation with IgA1 isolated from IgA nephropathy patients. J Immunol 2012;189:3751-3758.

-35 McAdoo SP, Bhangal G, Smith J, Taube D, Pusey CD, Tam FWK, Cook HT: Spleen tyrosine kinase (SYK) expression correlates with disease activity and outcome in glomerulonephritis spleen tyrosine kinase (SYK) expression in renal allograft rejection. American Society of Nephrology, Atlanta, 2013. J Am Soc Nephrol 2013;24:603A.

36 Smith J, Bhangal G, Syed A, Masuda ES, Cook HT, Hakim NS, Pusey CD, Tam FWK: Treatment with a spleen tyrosine kinase (SYK) inhibitor reduced the severity of experimental renal allograft rejection. American Society of Nephrology, San Deigo, 2012. J Am Soc Nephrol 2012;23:574A.

- 37 Ramessur Chandran S, Tesch GH, Han Y, Woodman N, Mulley WR, Kanellis J, Blease K, Ma FY, Nikolic-Paterson DJ: Spleen tyrosine kinase contributes to acute renal allograft rejection in the rat. Int J Exp Pathol 2015;96: 54-62.

-38 Snow AL, Martinez OM: Epstein-Barr virus: evasive maneuvers in the development of PTLD. Am J Transplant 2007;7:271-277.

- 39 Hatton O, Lambert SL, Phillips LK, Vaysberg M, Natkunam Y, Esquivel CO, Krams SM, Martinez OM: Syk-induced phosphatidylinositol-3-kinase activation in Epstein-Barr virus posttransplant lymphoproliferative disorder. Am J Transplant 2013;13:883-890.
40 McDaid JP, Smith J, Bhangal G, Yu M-C, McAdoo SP, Cook HT, Pusey CD, Masuda ES, Tam FWK. Reduction of renal fibrosis and TGF- $\beta$ production by late treatment with a spleen tyrosine kinase inhibitor in experimental glomerulonephritis. American Society of Nephrology, Philadelphia, 2011. J Am Soc Nephrol 2011;22:135A.

41 Ma FY, Blease K, Nikolic-Paterson DJ: A role for spleen tyrosine kinase in renal fibrosis in the mouse obstructed kidney. Life Sci 2016; 146:192-200.

42 Yang WS, Seo JW, Han NJ, Choi J, Lee KU, Ahn H, Lee SK, Park SK: High glucose-induced NF-kappaB activation occurs via tyrosine phosphorylation of IkappaBalpha in human glomerular endothelial cells: involvement of Syk tyrosine kinase. Am J Physiol Renal Physiol 2008;294:F1065-F1075.

43 Yang WS, Chang JW, Han NJ, Lee SK, Park SK: Spleen tyrosine kinase mediates high glucose-induced transforming growth factor- $\beta 1$ up-regulation in proximal tubular epithelial cells. Exp Cell Res 2012;318:1867-1876.

44 Colonna L, Catalano G, Chew C, D’Agati V, Thomas JW, Wong FS, Schmitz J, Masuda ES, Reizis B, Tarakhovsky A, Clynes R: Therapeutic targeting of Syk in autoimmune diabetes. J Immunol 2010;185:1532-1543.

45 Sweeny DJ, Li W, Clough J, Bhamidipati S, Singh R, Park G, Baluom M, Grossbard E, Lau DT: Metabolism of fostamatinib, the oral methylene phosphate prodrug of the spleen tyrosine kinase inhibitor R406 in humans: contribution of hepatic and gut bacterial processes to the overall biotransformation. Drug Metab Dispos 2010;38:1166-1176.

46 Martin P, Gillen M, Millson D, Oliver S, Brealey C, Grossbard EB, Baluom M, Lau D, Sweeny D, Mant T, Craven K: Effects of CYP3A4 inhibitors ketoconazole and verapamil and the CYP3A4 inducer rifampicin on the pharmacokinetic parameters of fostamatinib: results from in vitro and phase I clinical studies. Drugs R D 2016;16:81-92.

47 Martin P, Oliver S, Gillen M, Marbury T, Millson D: Pharmacokinetic properties of fostamatinib in patients with renal or hepatic impairment: results from 2 phase I clinical studies. Clin Ther 2015;37:2823-2836.

48 Martin P, Gillen M, Ritter J, Mathews D, Brealey C, Surry D, Oliver S, Holmes V, Severin P, Elsby R: Effects of fostamatinib on the pharmacokinetics of oral contraceptive, warfarin, and the statins rosuvastatin and simvastatin: results from phase I clinical studies. Drugs R D 2016;16:93-107.

49 Martin P, Gillen M, Millson D, Oliver S, Brealey C, Elsby R, Baluom M, Lau D, Mant $\mathrm{T}$ : Effects of fostamatinib on the pharmacokinetics of digoxin (a P-glycoprotein substrate): results from in vitro and phase I clinical studies. Clin Ther 2015;37:2811-2822.

50 McAdoo SP, Tam FW: Fostamatinib disodium. Drugs Future 2011;36:273.
51 Weinblatt ME, Kavanaugh A, Genovese MC, Musser TK, Grossbard EB, Magilavy DB: An oral spleen tyrosine kinase (Syk) inhibitor for rheumatoid arthritis. N Engl J Med 2010;363: 1303-1312.

52 Weinblatt ME, Genovese MC, Ho M, Hollis S, Rosiak-Jedrychowicz K, Kavanaugh A, Millson DS, Leon G, Wang M, van der Heijde D: Effects of fostamatinib, an oral spleen tyrosine kinase inhibitor, in rheumatoid arthritis patients with an inadequate response to methotrexate: results from a phase III, multicenter, randomized, double-blind, placebo-controlled, parallel-group study. Arthritis Rheumatol 2014;66:3255-3264.

53 Genovese MC, Kavanaugh A, Weinblatt ME, Peterfy C, DiCarlo J, White ML, O'Brien M, Grossbard EB, Magilavy DB: An oral Syk kinase inhibitor in the treatment of rheumatoid arthritis: a three-month randomized, placebo-controlled, phase II study in patients with active rheumatoid arthritis that did not respond to biologic agents. Arthritis Rheum 2011;63:337-345.

54 Genovese MC, van der Heijde DM, Keystone EC, Spindler AJ, Benhamou C, Kavanaugh A, Fudman E, Lampl K, O’Brien C, Duffield EL, Poiley J, Weinblatt ME: A phase III, multicenter, randomized, doubleblind, placebo-controlled, parallel-group study of 2 dosing regimens of fostamatinib in patients with rheumatoid arthritis with an inadequate response to a tumor necrosis factor- $\alpha$ antagonist. J Rheumatol 2014;41: 2120-2128.

-55 Skinner M, Philp K, Lengel D, Coverley L, Lamm Bergström E, Glaves P, Musgrove H, Prior H, Braddock M, Huby R, Curwen JO, Duffy P, Harmer AR: The contribution of VEGF signalling to fostamatinib-induced blood pressure elevation. Br J Pharmacol 2014;171:2308-2320.

-56 Kidney Disease: Improving Global Outcomes (KDIGO) Glomerulonephritis Work Group: KDIGO clinical practice guideline for glomerulonephritis. Kidney Int Suppl 2012;2: 139-274.

-57 Rauen T, Eitner F, Fitzner C, Sommerer C, Zeier M, Otte B, Panzer U, Peters H, Benck U, Mertens PR, Kuhlmann U, Witzke O, Gross O, Vielhauer V, Mann JF, Hilgers RD, Floege J; STOP-IgAN Investigators: Intensive supportive care plus immunosuppression in IgA nephropathy. N Engl J Med 2015;373:2225-2236.

58 Hogg RJ, Bay RC, Jennette JC, Sibley R, Kumar S, Fervenza FC, Appel G, Cattran D, Fischer D, Hurley RM, Cerda J, Carter B, Jung B, Hernandez G, Gipson D, Wyatt RJ: Randomized controlled trial of mycophenolate mofetil in children, adolescents, and adults with IgA nephropathy. Am J Kidney Dis 2015; 66:783-791.
Syk: A Crucial Player and Potential Therapeutic Target in Renal Disease
Nephron 2016;133:261-269 DOI: $10.1159 / 000446879$ 